\title{
A Preliminary Biogeochemical Study over the Uraniferous Quartz-Pebble- Conglomerate Zone near Kalasapura, Chickmagalur District, Karnataka, Southern India
}

\author{
B. C. Prabhakar'1, B. N. Rashmi1', R. V. Gireesh ${ }^{2}$ \\ ${ }^{1}$ Department of Geology, Bangalore University, Bangalore, India \\ ${ }^{2}$ Department of Geology, School of Earth Sciences, Central University of Karnataka, Kalaburgi, India \\ Email: bcprabhakar@rediffmail.com
}

Received 10 July 2015; accepted 13 September 2015; published 16 September 2015

Copyright (C) 2015 by authors and Scientific Research Publishing Inc.

This work is licensed under the Creative Commons Attribution International License (CC BY).

http://creativecommons.org/licenses/by/4.0/

(c) (;) Open Access

\begin{abstract}
Quartz-pebble-conglomerate (QPC) bearing unconformable zone at the base of Bababudan Group of rocks in Dharwar Craton in southern India is well known for its stratigraphic significance and uraniferous nature. Over this QPC zone, soil cover is very thin which is almost devoid of vegetation. A cursory biogeochemical study here indicated poor (170 to $520 \mathrm{ppb})$ uranium content in the scantily occurring herbs and shrub species as well as in the soil substratum (1.8 - 3.1 ppm). The values in plant species are much below the background values. Almost barren nature of soil surface and stunted growth of herb and shrub species suggested that geobotanical rather than biogeochemical study is more serviceable as a clue for the hidden QPC-type horizons, which quite often bear signatures of uranium mineralization.
\end{abstract}

Keywords

Biogeochemistry, Bababudan, Dharwar Craton, Uranium Mineralization

\section{Introduction}

Base of the Bababudan Group ( 2.7 Ga) in Dharwar craton in southern India is represented by Quartz-pebbleconglomerate (QPC) which is well exposed near Kalasapura. It represents an unconformity between the base-

How to cite this paper: Prabhakar, B.C., Rashmi, B.N. and Gireesh, R.V. (2015) A Preliminary Biogeochemical Study over the Uraniferous Quartz-Pebble-Conglomerate Zone near Kalasapura, Chickmagalur District, Karnataka, Southern India. International Journal of Geosciences, 6, 987- 992. http://dx.doi.org/10.4236/ijg.2015.69078 
ment gneisses and Dharwar Supergroup. This conglomerate horizon has been traced for a strike length of over $34 \mathrm{~km}$ forming the base for schistose rocks of Bababudan Group (Figure 1). Detrital uraninite $\left(\mathrm{UO}_{2}\right)$ is found to occur in these QPC along with pyrite. Possibility of Au and PGEs is also speculated in this horizon [1]. As the study area is chiefly made up of QPC, the soil is gravelly, with poor humus content. The dispersal of uranium content into soil is mostly in the form of finer detrital fractions of uraninite, but due to strong silicic fractions of soil and poor weathering effects, the same (uranium) is not available easily to plants. However, owing to its (uranium) mobile nature, and as this area is well known to be a uranium tract, an attempt has been made to check the level of its concentration in plants and soil through random sampling in selected areas near Kalasapura, as a preliminary step to envisage a detailed study.

\section{Field Setting and Geobotanical Features}

The QPC zone expresses itself as a narrow low lying mound at an altitude of $600 \mathrm{~m}$ MSL and runs as a continuous stretch. However, it is well exposed between Kalasapura and Karthikatte (Figure 2). In the present study, only a small section of this long stretch has been selected for investigation. The selected section stretches from Kalasapura to Karthikatte covering a distance of about $6 \mathrm{~km}$. Geomorphologically, the area forms the fringe zone of "Malnad" (the mountainous tract in southern Karnataka) and it receives fairly good annual rainfall ( $~ 800$ $\mathrm{mm}$ ). The natural vegetation in the selected stretch is very poor, mostly due to the dominant siliceous nature of bed rocks and thin soil cover (Figure 3). The sparsely noticed plant species, in this otherwise poorly vegetated area, included Chromolaena odarata, Hyptis suvaeloens, Vicoa indica, Dodonoaea viscosa and Grass. There was no homogeneity in their distribution. Even the sparsely found plant species exhibited stunted growth. The herb species showed slightly better thriving. The observed shrub and herb species have been sampled and determined for their trace element contents. An attempt was also made to measure the natural radioactivity in this area, by using scintillation counter. This reconnaissance study has revealed higher counts of radioactivity (23 50 ohms $/ \mu \mathrm{R}$ ) all along the studied QPC horizon between Kalasapura and Karthikatte.

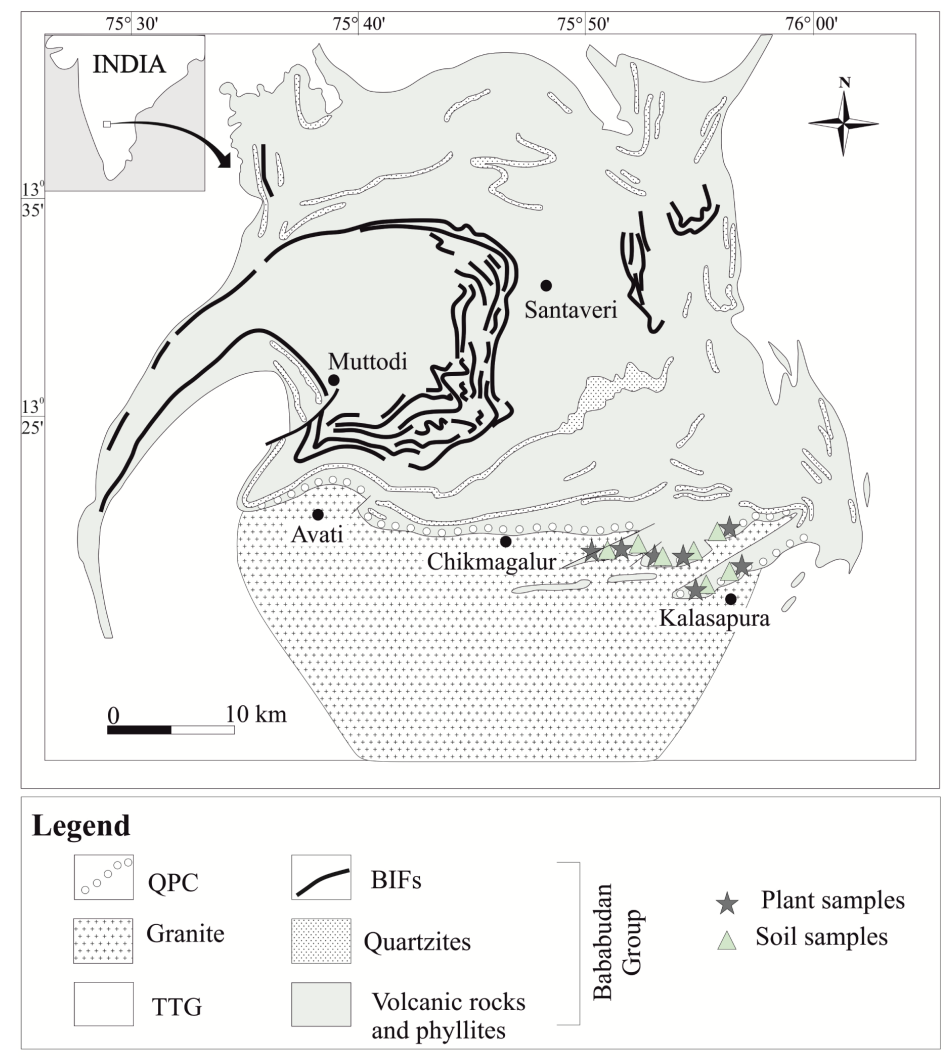

Figure 1. Geological sketch map of Kalasapura area showing sample locations (modified after Chardon et al., 1998 [2]). 


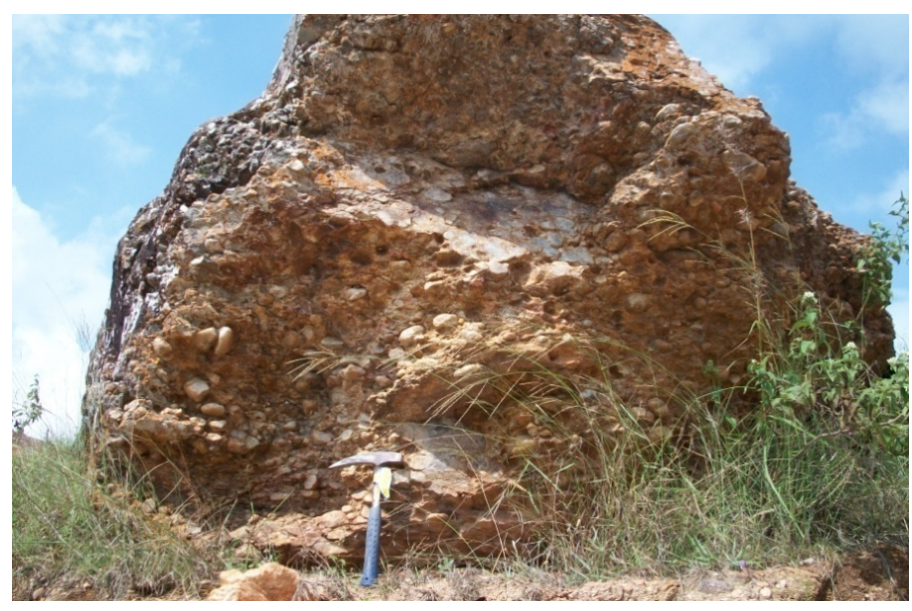

Figure 2. An outcrop of quartz-pebble-conglomerate exposed in a road cut near Kalasapura.

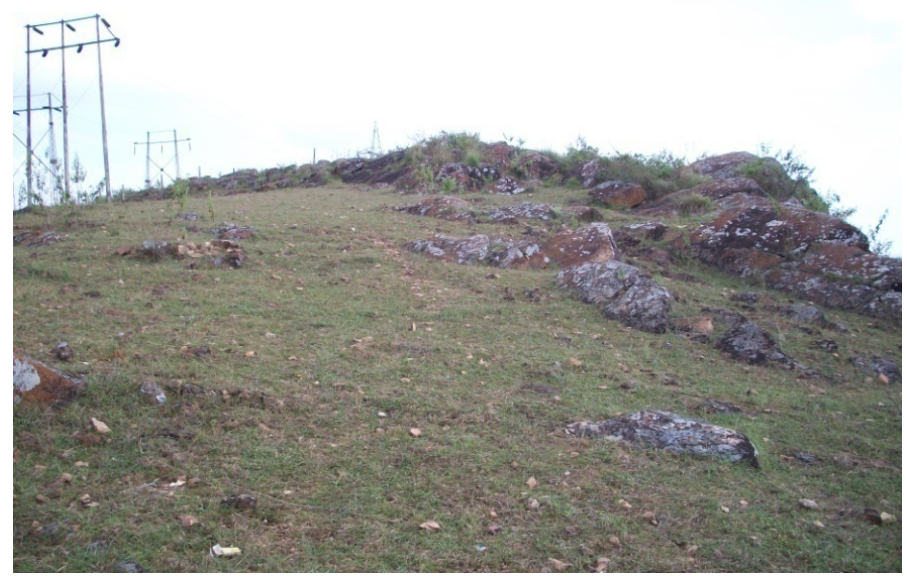

Figure 3. Very poor vegetation over QPC zone near Kalasapura.

\section{Sampling and Analytical Methods}

Considerable part of the studied area has good accessibility for field work and sampling. The sampling procedures followed for plant species are as enumerated in Brooks [3]. Before sampling, the mineralized area was appraised for different aspects like the nature of soil profile, the possibility of contamination of overburden due to weathering, the vegetation density, homogeneity, variability of species, geomorphic conditions, drainage system, full bloom periods of plants etc. The field work was conducted during post monsoon in November/December, when most of the herb and shrub group of plants had reached their full bloom period and the sampling took minimum time to ensure the least climatic variation that could influence elemental uptake by plants. A rectilinear asymmetrical grid sampling pattern was used and the profiles were laid perpendicular to the strike of the QPC zone. The density and homogeneity of vegetation was thoroughly evaluated before sampling. Precautions like 1) sampling the same species of plants, 2) sampling the same organs of plants, 3) recognizing the same growth level of plants and 4) similar appearance and health of the plants were kept in mind while sampling. At selected points, along the transect lines, soil samples were also collected for trace element analysis, since strong correlation exists between soil and metal concentration in plants [4] [5]. During sampling, care was taken to observe any visible signs of morphological anomalies.

\section{Analytical Procedure}

The plant samples were dried, pulverized, ashed and subsequently decomposed by hot acid treatment. $0.5 \mathrm{~g}$ plant 
ash was digested in $\mathrm{HF}$ and $\mathrm{HNO}_{3}$ mixture and evaporated. The residue was digested three times with nitric acid and taken in $10 \% \mathrm{HNO}_{3}$. An aliquot of the sample solution was taken in a $60 \mathrm{ml}$ separating funnel. Uranium was extracted into $5 \mathrm{ml}$ of $3 \%$ cyclohexane. Then it (uranium) was back extracted into $5 \mathrm{ml}$ of $5 \%$ sodium pyrophosphate. Then this was made up to $10 \mathrm{ml}$. Uranium fluorescence was measured by laser flourimeter with suitable calibration standards and unknown concentration of uranium in sample was calculated. Other elements like $\mathrm{Cr}, \mathrm{Zn}, \mathrm{Mn}, \mathrm{Co}$, and Ni have been analyzed by AAS by following the procedure as mentioned in Rashmi et al. [6].

The soil samples were ground to -200 mesh by jaw crusher and further fine-ground to -250 mesh by agate mortar. $0.5 \mathrm{gm}$ of the finely ground samples were digested (separately) in hydrofluoric and nitric acid mixture and evaporated. After evaporation, again the residue was digested three times in nitric acid and taken in $10 \%$ nitric acid. The uranium was extracted into ethyl acetate and aliquot of the organic layer was pipetted into a small platinum dish and evaporated. It was fused with sodium carbonate, potassium carbonate and sodium fluoirde flux at $700^{\circ} \mathrm{C}$. The fluorescence of the bead was measured using fluorimeter and compared with a standard. From these standard values, concentration of uranium in the samples was calculated.

The analytical data for both plant and soil samples are presented in Table 1 and Table 2 respectively. The elemental concentration in these samples is discussed below.

\section{Discussion on Elemental Behaviour}

The studied species included Dodonaea viscosa, Chromoleaena odorata, Hyptis suvaeleoens, Vicoa indica and a grass species. Analysis for limited samples of plants and soil has been carried out for elements like Cr, Zn, Mn, $\mathrm{Co}$, Ni along with $\mathrm{U}$. While $\mathrm{Cr}$ and $\mathrm{Mn}$ are reflected well in all the analysis, $\mathrm{Ni}$ and $\mathrm{Co}$ are indicated only in one sample. Zn values are detected in only 3 samples. The high values (69 - $199 \mathrm{ppm}$ ) of $\mathrm{Cr}$ are intriguing because, plants normally would have very low $\mathrm{Cr}$ content, more so in areas where siliceous substratum exists, like the one found in the study area. These high values could in all probability indicate higher Cr content in the soil substratum, and these higher values could have been derived from the mafic/ultramafic sources with which QPC is closely associated. Mn, being one of the important nutrients for plants would normally be in higher concentration and thus modest to high values of $\mathrm{Mn}$ in the plant species of the present study reflect the normal up taking behaviour of plants for this metal. $\mathrm{Zn}$ being a moderately mobile element can become available as plant nutrient as $\mathrm{Zn}$ sulfate or $\mathrm{Zn}$ carbonate in soil. In the present study, modest $\mathrm{Zn}$ concentration is noticed only in 4 plant species and indicates poor bedrock source of this metal. Its mobility could also have been affected, as it may be

Table 1. Trace element content of plants in uraniferous area of Kalasapura (all values in ppm, except U).

\begin{tabular}{cccccccc}
\hline Sample No. & Plant name & Cr & Zn & Mn & Ni & Co & U (ppb) \\
\hline 1 & Grass & 200 & & 3404 & - & - & 270 \\
2 & Dodonaea viscosa & 77 & 74 & 694 & - & - & 380 \\
3 & Chromolena odarata & 70 & & 548 & - & - & 170 \\
4 & Hyptis suvaeolens & 93 & 39 & 750 & - & - & 320 \\
5 & Vicoa inidica & 86 & 226 & 1770 & 24 & 105 & 520 \\
6 & Vicoa inidica & 87 & 123 & 934 & - & - & 470 \\
\hline
\end{tabular}

Table 2. Uranium content in Soil samples of Kalasapura area.

\begin{tabular}{rrrr}
\hline Sample No. & U in soil (ppm) \\
\hline 1 & 2 & 2.0 & 1.8 \\
3 & 2.5 & 2.3 \\
4 & 3.1 \\
5 & 6 & 1.8 \\
\hline
\end{tabular}


absorbed by $\mathrm{MnO}_{2}$ complexes and insoluble organic matter in the soil [7], which could affect its availability as plant nutrient. Quite surprisingly Ni and Co are indicated in one sample i.e., Vicoa Indica. Ni has a closer affinity to occur in ultramafic rocks in appreciable quantities ( 2000 ppm). Co also shows relatively higher concentration $(\sim 110 \mathrm{pm})$ in ultramafic rocks. Like Cr concentration, as explained earlier, Ni and Co concentration too could have been derived by the admixed and localized ultramafic fractions in the substratum. It is also interesting to note that $\mathrm{Ni}$ and $\mathrm{Co}$ are enriched in one plant species i.e. Vicoa Indica which is reported to be a local indicator for Ni [8]. Its ability for preferential up-taking of this metal is also reflected here, because when other plants could not uptake the otherwise scantily available Ni in the siliceous bedrocks, Vicoa Indica has up taken it preferentially.

Uranium showed moderate, but almost consistent levels of concentration in all the sampled plant species and also soil samples. However, compared to normal distribution (0.6 ppm) of U in plants [7], the values in the analysed samples are poorer. However, soil samples show elevated values (Figure 4) clearly indicating the uraniferous nature of bedrocks. $\mathrm{U}$ in the surface, during wreathing, could constitute complex carbonates, phosphates and silicates. Thus, more common aqueous species of $\mathrm{U}$ are $\mathrm{UO}_{2}, \mathrm{UO}_{2} \cdot\left(\mathrm{CO}_{3}\right)_{3}, \mathrm{UO}_{2} \cdot\left(\mathrm{CO}_{2}\right)_{2}$, and $\mathrm{UO}_{2} \cdot\left(\mathrm{HPO}_{4}\right)_{2}$ in the surface condition. These species, when in soil, could precipitate in the root tip of plants as autunite (Ca $\left(\mathrm{UO}_{2}\right)_{2} \cdot \mathrm{PO}_{4}$ and part of it could enter into plant system. The acid condition in the siliceous substratum could have also helped some part of the uranium in the substratum to be leached away, because $U$ becomes more mobile in acid-rich waters. Lack of significant organic matter and Fe-oxides in the substratum also would have allowed part of $U$ to be drained out of the system. Otherwise, the soil samples should have contained still higher content of $\mathrm{U}$, because it is a uraniferous zone.

However, as mentioned earlier poorer uptake of $U$ by plants is puzzling, which could be due to 1) either strong silica-rich ground which has resisted intense weathering and the consequent poor soil profile development and 2) hydromorphic leaching in the gravelly soil. Thus, the above two conditions could have hindered active root-bedrock interaction inhibiting effective $\mathrm{U}$ up taking by plants.

\section{Conclusions}

This preliminary study in the uranium tract of Kalasapura area has shown that poorly weathered silica-rich substratums do not support good vegetation growth. This indication could in turn serve as a first approximation for detailed investigation in any new similar area for uranium exploration. Though it is difficult to characterize biogeochemical behaviour with limited analysis, the lower content of metals reflects on very poor soil profile

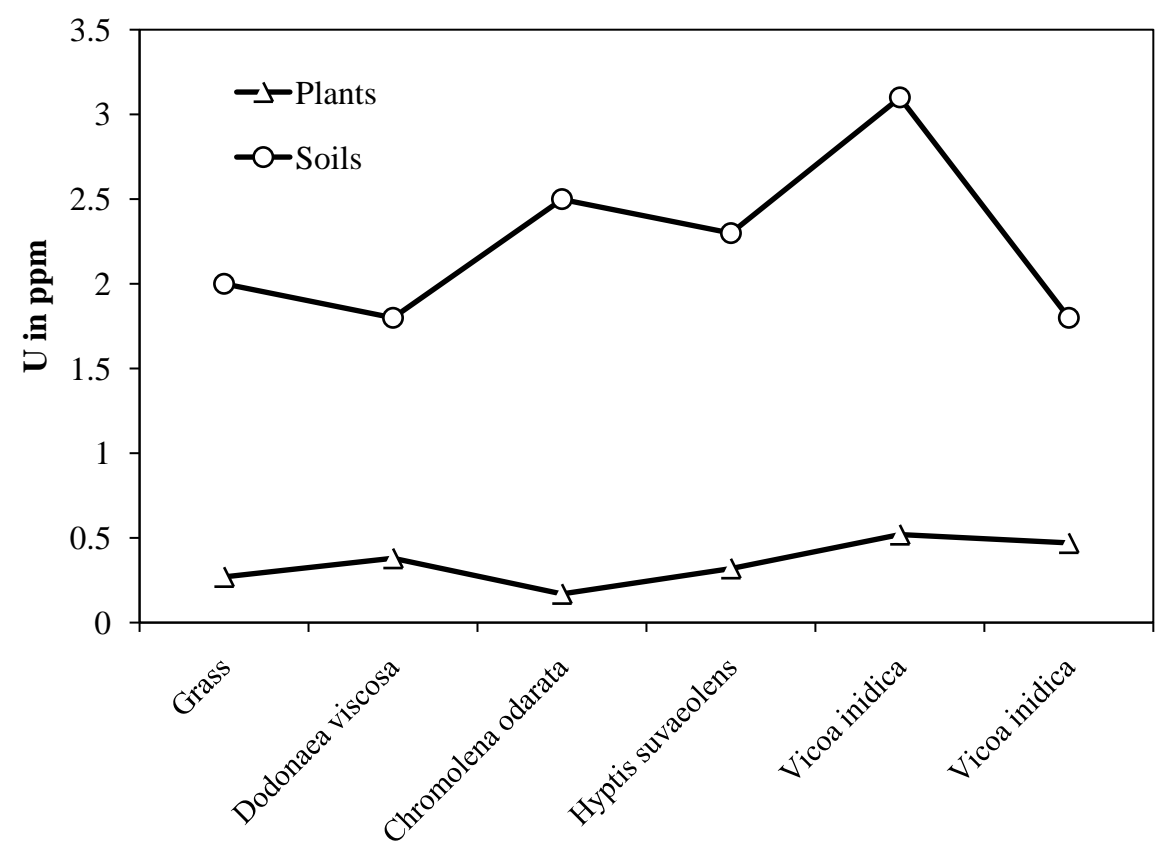

Figure 4. Plot showing comparison of uranium content in plants and soil. 
development and lack of rich metal fractions in bedrocks. However relatively (to plants) higher U content in the bedrocks is better manifested in bulk soil samples. Poor reflection of $U$ in plants suggests that biogeochemical studies, in areas like this, will not be directly useful, rather soil geochemistry is more serviceable. However, detailed soil sampling and sampling by trenching should provide a better picture of $\mathrm{U}$ concentration in bedrocks. This would also help to understand the dispersion of $U$ and its availability to plants for up taking.

\section{References}

[1] Radhakrishna, B.P. (1996) Mineral Resources of Karnataka. Geol. Soc. India pub., Bangalore.

[2] Chardon, D., Choukroune, P and Jayananda, M (1998) Sinking of the Dharwar Basin (South India): Implications for Archaean Tectonics. Precambrian Research, 91, 15-39. http://dx.doi.org/10.1016/S0301-9268(98)00037-0

[3] Brooks, R.R (1972) Geobotany and Biogeochemistry in Mineral Exploration. Harper and Row Publishers, New York, 290.

[4] Brooks, R.R. and Yang, X.H. (1984) Elemental Levels and Relationships in the Endemic Serpentine Flora of the Great Dyke, Zimbabwe and Their Significance as Controlling Factors for the Flora. Taxon, 33, 392-399. http://dx.doi.org/10.2307/1220976

[5] Kovalevsky, A.L. (1987) Biogeochemical Exploration for Mineral Deposits (Brooks, R.R., Ed.). 2nd Edition, Trans. Russia, VNU Science Press, Utrecht, Vol. 224.

[6] Rashmi, B.N., Prabhakar, B.C., Gireesh, R.V., Suresh, B., Nijagunaiah, R. and Ranganath, R.M. (2010) Geobotanical and Biogeochemical Study of Chromite Bearing Areas of Nuggihalli Schist Belt, Karnataka. Current Science, 99, 619-627.

[7] Rose, A.W., Hawkes, H.E. and Webb, J.S. (1990) Geochemistry in Mineral Exploration. Academic Press, Waltham, MA.

[8] Rashmi, B.N., Prabhakar, B.C., Gireesh, R.V., Nijagunaiah, R and Ranganath, R.M. (2009) Nickel Anomalies in Ultramafic Profiles of Jayachamarajapura Schist Belt, Western Dharwar Craton. Current Science, 96, 1512-1517. 